\title{
Stage I Pleural Malignant Mesothelioma AJCC v7
}

National Cancer Institute

\section{Source}

National Cancer Institute. Stage I Pleural Malignant Mesothelioma A/CC v7. NCI

Thesaurus. Code C6646.

Stage I includes: (T1, N0, M0); IA: (T1a, N0, M0); IB: (T1b, N0, M0). T1: Pleural mesothelioma with a tumor limited to the ipsilateral parietal pleura with or without mediastinal pleura and with or without diaphragmatic pleural involvement. T1a: Pleural mesothelioma with no involvement of the visceral pleura. T1b: Pleural mesothelioma with a tumor also involving the visceral pleura N0: No regional lymph metastasis. M0: No distant metastasis. (AJCC 7th ed.) 